\title{
PRÁTICAS DE LOGÍSTICA REVERSA DE AUTOMÓVEIS EM FIM DE VIDA: ESTUDO COMPARATIVO COM O MODELO ALEMÃO DE DESTINO DE VEÍCULOS EM FIM DE VIDA
}

\author{
Mateus Wieser Pamplona ${ }^{1}$ \\ Rodrigo Catafesta Francisco ${ }^{2}$ \\ Jaqueline $\mathrm{Hertel}^{3}$ \\ Joel Dias da Silva ${ }^{4}$
}

\section{Resumo}

Frente ao crescimento do mercado automobilístico mundial, a preocupação com a reutilização dos insumos na fabricação de um automóvel está cada vez mais evidente. Neste contexto, o presente trabalho tem como objetivo comparar as práticas de logística reversa para os veículos em fim de vida em Blumenau e na Alemanha. A abordagem se justifica pelo grande potencial de geração de veículos em fim de vida, uma vez que o município de Blumenau apresenta uma média de automóveis por habitante 1,7 vezes superior à média nacional. Buscou-se, através de um levantamento bibliográfico, levantar informações a respeito das características do processamento de veículos em fim de vida, seguido de um questionário aplicado às empresas de ferro-velho da cidade. Verificou-se que o manuseio de veículos em fim de vida em Blumenau é feito apenas com o propósito de revenda das peças retiradas. Já no país europeu, o foco é a reutilização das matérias-primas, principalmente pela reciclagem e pelo reaproveitamento energético. Instrumentos legais específicos, maior número de informações para as empresas, incentivos governamentais, simplificação do processo de reciclagem e maior contato empresa-cliente foram observados na Alemanha, enquanto que o mesmo não ocorre em Blumenau. Um cenário diferenciado como este poderia fazer com que o automóvel em fim de vida voltasse à cadeia produtiva, fechando assim o ciclo de vida de uma forma mais rápida e eficiente do que a simples revenda no mercado secundário.

Palavras-chave: Veículos em fim de Vida. Logística reversa. Reciclagem de Automóveis. 


\section{INTRODUÇÃO}

No ano de 2013, o mercado automotivo apresentou aproximadamente 85,5 milhões de novos registros de veículos no mundo, dos quais aproximadamente 3,6 milhões foram no Brasil(VDA,2014).Diante deste cenário,surge a preocupação com o destino dos veículos que saem de circulação para que estes novos entrem em seu lugar.

Alguns países, como os membros da União Europeia, por exemplo, conscientes da importância do tema, têm, por meio da Diretiva 2000/53/EU, uma maneira de regulamentar o destino final de automóveis com idade avançada. De acordo com o BMU (Bundesministerium für Umwelt, Naturschutz und ReaktorsicherheitMinistério do Meio Ambiente, Conservação e Segurança Nuclear), a Alemanha tem destaque na atuação e influência neste contexto,ocupando a terceira posição entre os países membros da UE em reutilização e valorização dos Veículos em fim de Vida - VFV (MILDEMBERGER, 2012 apud BMU,2011). Por este motivo, o país serve de modelo para que outros, assim como o Brasil, que ainda estão iniciando neste mercado, possam adotar práticas semelhantes.

Os AUTOMÓVEIS EM IDADE AVANÇADA SÃO UM GRANDE PROBLEMA COMO MEIO DE TRANSPORTE E TAMBÉM COMO DESCARTE. QUANDO AINDA EM USO NAS RUAS, UM DOS GRANDES PROBLEMAS É A POLUIÇÃO AMBIENTAL.
Com o intuito de estipular metas para o desempenho ambiental dos automóveis, o CONAMA (Conselho Nacional do Meio Ambiente) criou, em 1986, o Programa de Controle de Poluição dos Veículos Automotores (PROCONVE). Segundo o relatório do programa, em 1996, o limite de emissão de $\mathrm{CO}$ para um veículo leve, por exemplo, era de $24 \mathrm{~g} \cdot \mathrm{km}^{-1}$ (gramas por quilômetro) (IBAMA, 2011, p. 36). A meta mais recente estipulada, que é obrigatória para todos os automóveis comercializados em 2015, é de 1,30 g. $\mathrm{km}^{-1}$ de CO (IBAMA, 2015). Isso representa apenas 5\% da emissão do ano de 1996 e mostra o peso ambiental que estes veículos representam.

Com o descarte, a permanência prolongada de veículos expostos ao clima, como é o caso dos abandonados e depositados em ferros-velhos, por exemplo, tem causado contaminação do solo e dos lençóis freáticos pela penetração de fluidos oriundos destes (JOAQUIM FILHO, 2012).

Neste cenário, a Logística Reversa, descrita como o retorno dos produtos à indústria depois doconsumo(BARCELLOS,2013), surge como ferramenta para auxiliar a reverter a situação atual e aproveitar a oportunidade de negócio gerada, tanto pela dimensão do mercado, quanto pelas diretivas e leis que vem sendo criadas, como foi apontado anteriormente. Em 2010, foi aprovada, no Brasil, a Política Nacional de Resíduos Sólidos (PNRS). A Lei 12.305, de 02, de agosto de 2010, regulamentou o compromisso das empresas com a logística reversa de seus produtos, estipulando meta de 
20\% de reciclagem. Em 2015, esta lei entrou em vigor para alguns setores da economia, como os de pilhas e baterias, pneus inservíveis e lâmpadas (BARCELLOS, 2013). Apesar do setor automobilístico não estar incluso atualmente na PNRS, foi aprovado, no Senado Federal, o Projeto de Lei (PLS) 67/13, que visa incluí-lo (BRASIL, 2015).
Assim, com o intuito de verificar os procedimentos adotados no descarte e valorização dos VFV no município de Blumenau, em Santa Catarina, bem como o potencial da região no segmento, propõe-se uma atividade de pesquisa para análise da região, que seguida de comparação com modelos em uso na Alemanha, identifique possibilidades de melhoria e que contribuam com o desenvolvimento econômico-sustentável da região.

\section{O PROCESSO DE RECICLAGEM DE UM VEÍCULO}

O processo tradicional de beneficiamento de um veículo, para que possa ser aproveitado pelas indústrias como material reciclado acontece, segundo Leite (2009,), de maneira resumida em 6 estágios, detalhada e esquematizada na Figura 1 , com os subprodutos e processos resultantes.

Figura 1: Fluxograma de processo de reciclagem de VFV

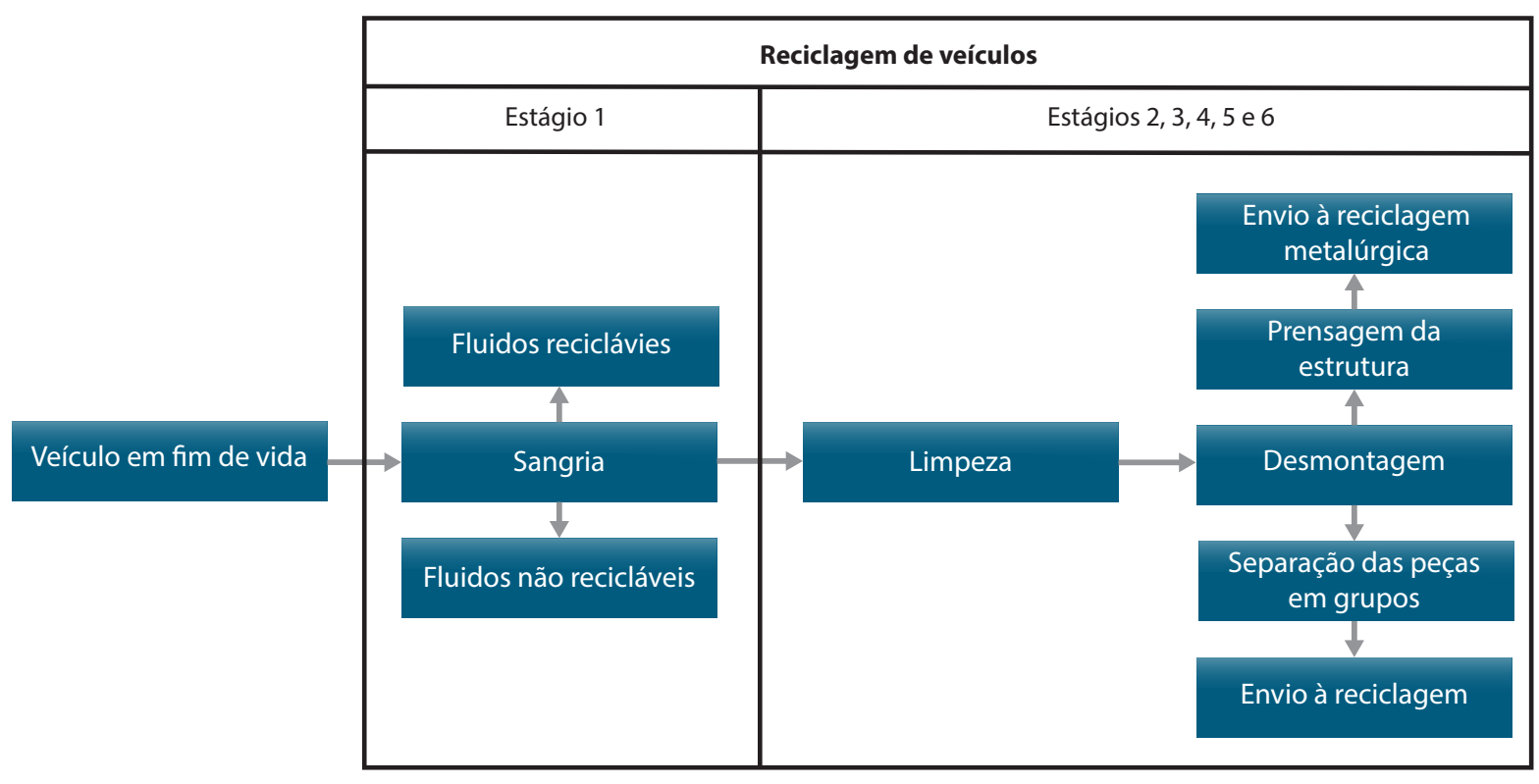

Fonte: Adaptado de Leite (2009) 
No estágio 1, os automóveis passam pelo processo de sangria, no qual todos os fluidos, como óleos lubrificantes, combustível remanescente e fluidos refrigerantes, são completamente removidos da estrutura e encaminhados às empresas responsáveis pela sua reciclagem e/ou disposição final. Leite (2009) ressalta que algumas sobras não poderão ser enviadas para reciclagem e, neste caso, deverão ser encaminhadas a aterros de rejeitos ou à incineração.

Já no estágio 2, idealmente dentro de uma linha de desmontagem apropriada, o carro é limpo e, em seguida, realiza-se a desmontagem dos painéis e bancos. À medida em que as peças são retiradas durante todo o processo de desmontagem, elas são prontamente separadas em diversos grupos de materiais (plástico, vidro, borrachas, entre outros) para que, posteriormente, seja realizada a venda.
No estágio 3, as partes de fronteira do veículo, como portas, capô e porta-malas são desmontadas. Este processo dá início à coleta do material reciclável (metais ferrosos e não ferrosos) mais abundante e que apresenta maior vantagem em termos de economia energética e de custos.

O estágio 4 representa um sistema giratório pelo qual o veículo passa para facilitar a remoção das peças dos estágios que se seguem. No estágio 5 , serão removidos o motor e a transmissão do veículo. Por fim, no sexto e último estágio, a estrutura do veículo (carcaça) está pronta para ser prensada, material que em seguida será encaminhado à reciclagem metalúrgica.

É conveniente apresentar também, para servir de base para o estudo feito, um esquema de uma empresa de desmanche de automóveis, para facilitar a visualização de uma linha de desmanche, apresentada na Figura 2.

Figura 2: Operações de desmanche de automóveis

Esquema das operações de desmanche de automóveis

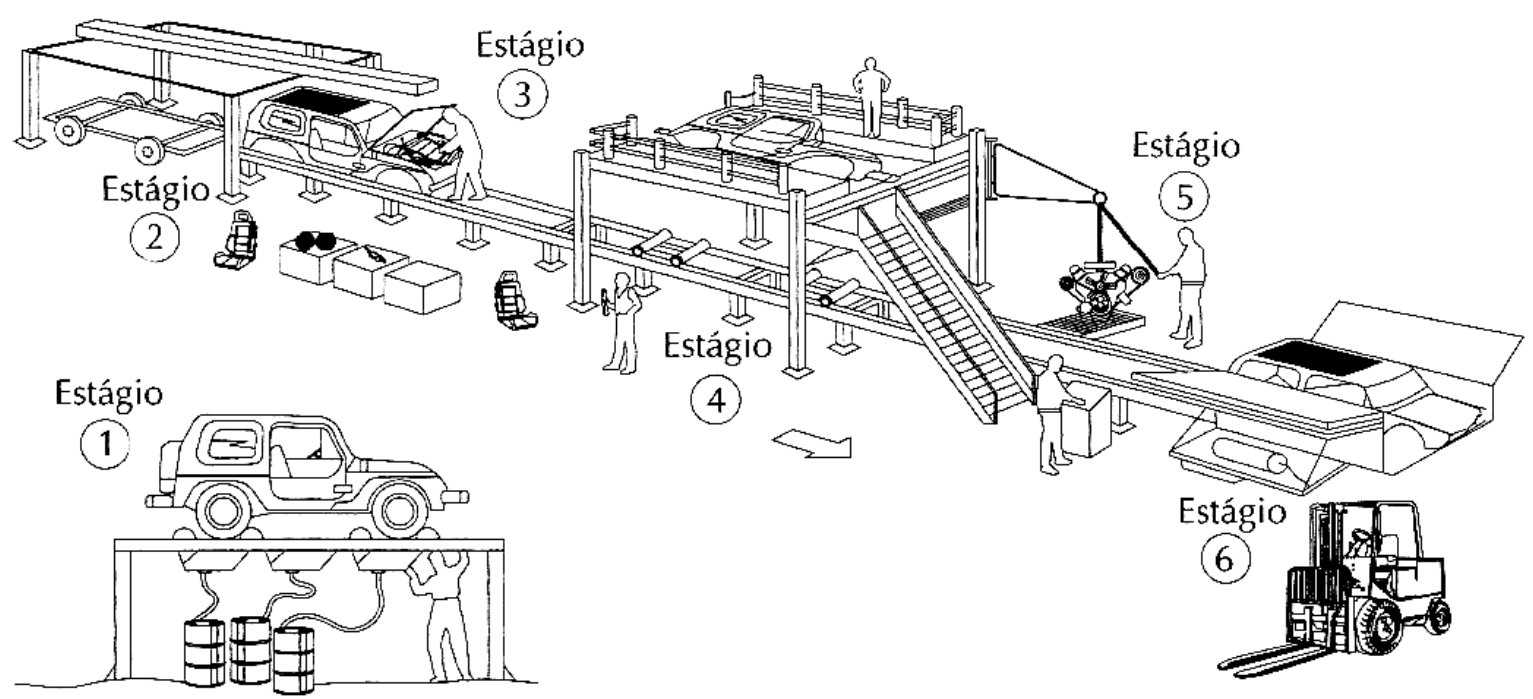

Fonte: Adaptado de Leite (2009) 


\section{LOGÍSTICA REVERSA}

De maneira mais específica, costuma-se definir logística reversa como sendo

A área da logística empresarial que planeja, opera e controla o fluxo e as informações logísticas correspondentes, do retorno dos bens de pós-venda e de pós-consumo ao ciclo de negócios ou ao ciclo produtivo, por meio dos canais de distribuição reversos, agregandothes valores de diversas naturezas: econômico, de prestação de serviços, ecológico, legal, logístico de imagem corporativa, dente outros. (LEITE, 2009, p. 17).

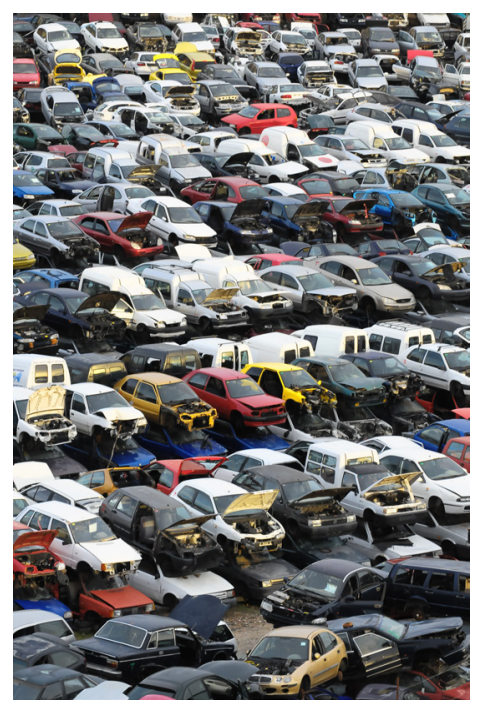

É possível entender que, pelas definições, que o objetivo da LR é tornar possível o retorno dos materiais de pós-consumos e pós-venda ao ciclo produtivo ou de negócio, estando em sintonia com o que preconiza a Política Nacional de Resíduos Sólidos - PNRS, quando a caracteriza como um dos instrumentos para aplicação da responsabilidade compartilhada pelo ciclo de vida dos produtos.
A PNRS (BRASIL, 2010)

DEfine A LOGÍSTICA REVERSA

COMO UM"INSTRUMENTO

DE DESENVOLVIMENTO

ECONÔMICO E SOCIAL

CARACTERIZADO POR UM

CONJUNTO DE AÇÕES,

PROCEDIMENTOS E MEIOS

DESTINADOS A VIABILIZAR

A COLETA E A RESTITUIÇÃO

DOS RESÍDUOS SÓLIDOS AO

SETOR EMPRESARIAL, PARA

REAPROVEITAMENTO, EM

SEU CICLO OU EM OUTROS

CICLOS PRODUTIVOS, OU

OUTRA DESTINAÇÃO fINAL

AMBIENTALMENTE ADEQUADA".

A PNRS (BRASIL, 2010) define a logística reversa como um "instrumento de desenvolvimento econômico e social caracterizado por um conjunto de ações, procedimentos e meios destinados a viabilizar a coleta e a restituição dos resíduos sólidos ao setor empresarial, para reaproveitamento, em seu ciclo ou em outros ciclos produtivos, ou outra destinação final ambientalmente adequada”.

Desta forma, é importante que o processo agregue algum valor significativo para a empresa, seja ele econômico ou não. 


\section{VFV NA ALEMANHA}

$\mathrm{Na}$ Alemanha, é de responsabilidade do consumidor levar o VFV até um dos desmanteladores disponíveis no país.Para tanto, sites como o Arge-Altauto e GESA, por exemplo, disponibilizam um banco de dados onde o consumidor, a partir do seu endereço residencial, localiza os pontos mais próximos para o descarte. Geralmente, estes não ficam distantes mais do que $50 \mathrm{~km}$ da residência do consumidor. No caso da GESA, é possível também especificar o fabricante do automóvel, fazendo com que o programa localize parceiros da marca fabricante e que coletam o carro gratuitamente, também chamados de Kostenlose Rücknabme.

Após ser recebido pelo desmantelador, o veículo é desmanchado e os metais provenientes deste processo, que representam em média 75,5\% do peso total (UBA; BMU, 2015), seguem para empresas de shredding (termo em inglês para o processo de trituração em máquinas especializadas), resultando em pequenos fragmentos.

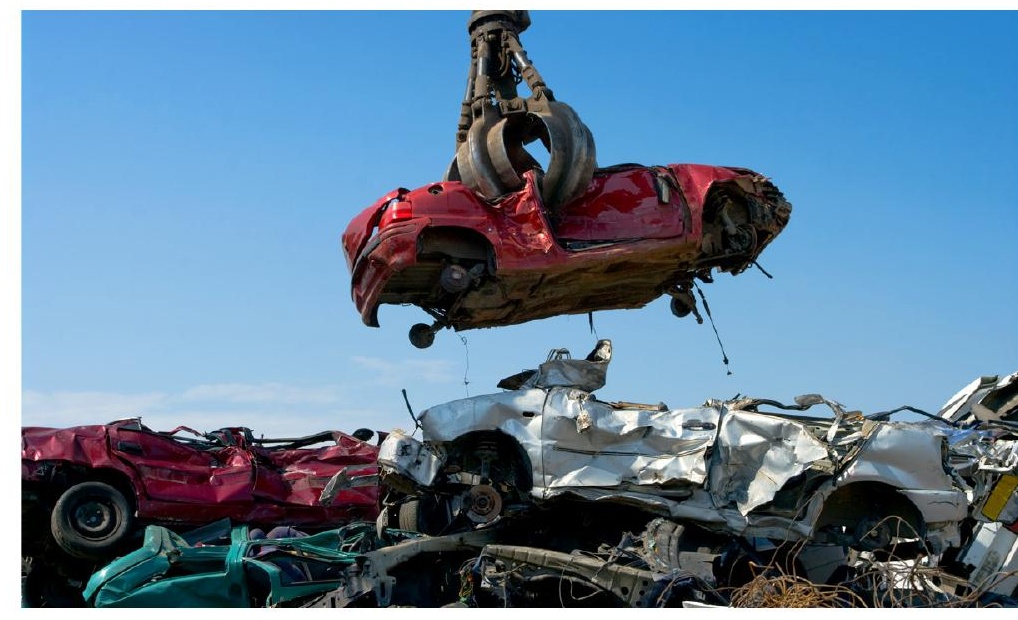

Após isso,os fragmentos passarão pelo processo de separação metálica, resultando em três grupos: as sucatas ferrosas (aços), as sucatas não ferrosas (alumínio, cobre, zinco, chumbo etc.) e a fração leve, termo utilizado para denominar o rejeito do processo. Após serem vendidos, estes fragmentos são reutilizados conforme apresentado na Figura 3.

Figura 3: Destino dos fragmentos metálicos na Alemanha

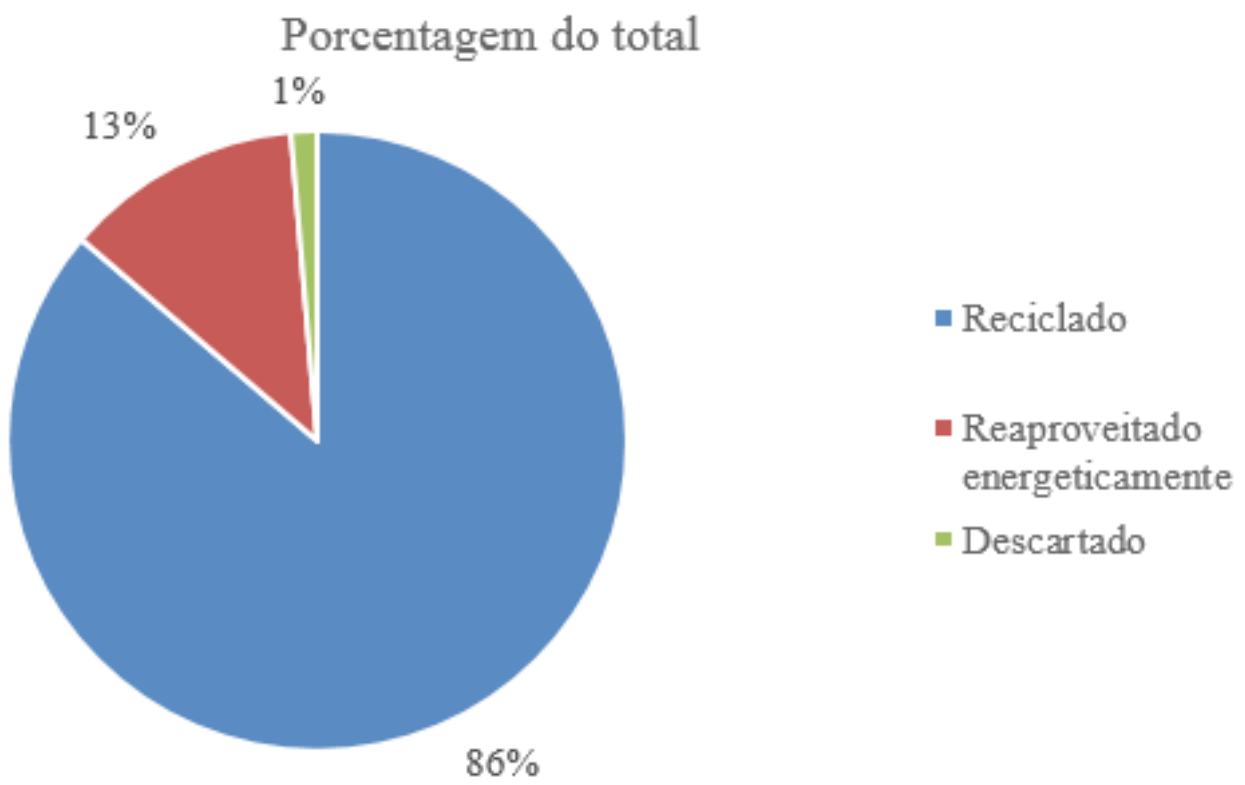

Fonte: Adaptado de UBA; BMU (2015) 
De maneira análoga, os subprodutos não metálicos também são agrupados e enviados à reciclagem ou ao reaproveitamento energético, conforme a Figura 4, que mostra o destino em porcentagem destes componentes.

Figura 4: Distribuição da fração não metálica em relação ao destino final

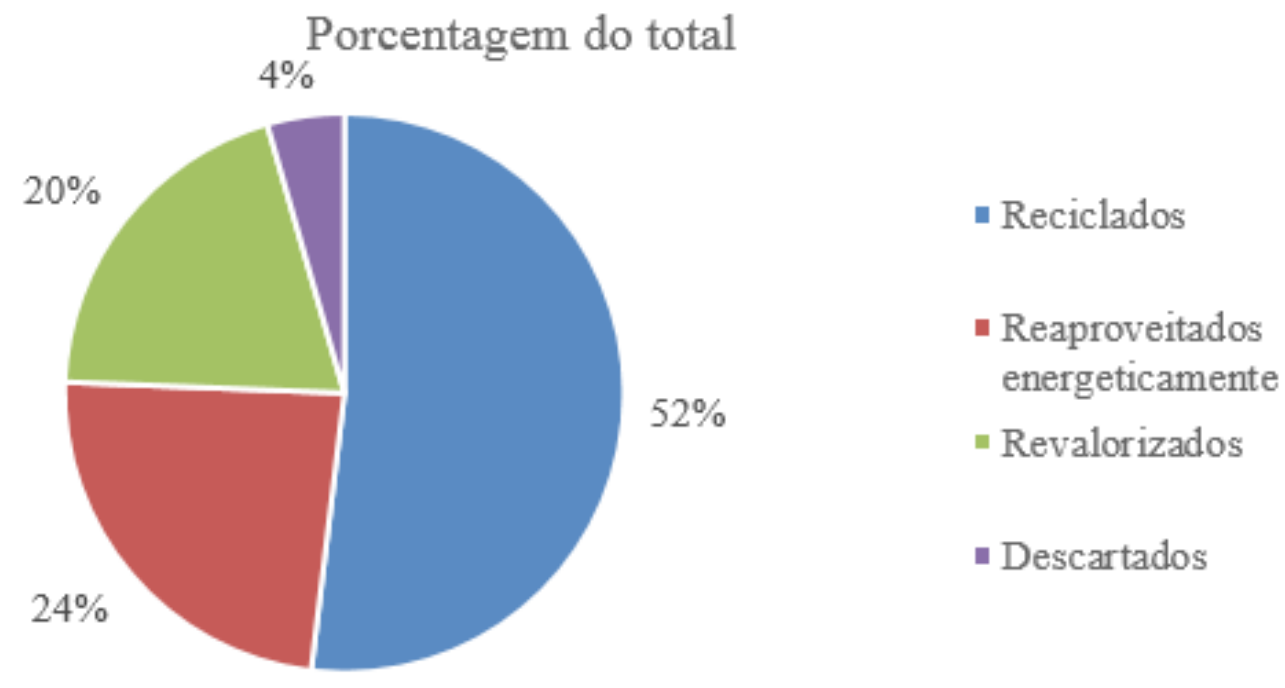

Fonte: Adaptado de UBA; BMU (2015)

\section{METODOLOGIA}

Utilizando como base os conceitos ora apresentados, propôs-se uma pesquisa para analisar o processo atual de destinação final dos VFV na região de Blumenau.

O cenário a ser discutido foi estabelecido através de um questionário padrão (Figuras 3, 4, e 5) aplicado in loco. A sequência de perguntas buscou coletarinformações sobre o recebimento do VFV, seu processamento e o destino dado pelas empresas, como também os métodos em uso atualmente.

Os dados permitiram a comparação com os processos e métodosjá utilizados na Alemanha.

Por fim, utilizou-se também o procedimento de análise do tipo Survey, que é um método adequado em trabalhos desta natureza, especialmente, segundo Freitas et al. (2000), quando:

a) se tem o desejo de responder questões nas quais o foco de interesse é o que está acontecendo, ou como e por que isso está acontecendo;

b) o ambiente natural é a melhor situação para estudar o fenômeno de interesse;

c) o objeto de interesse ocorre no presente ou passado próximo.

Esta pesquisa enquadra-se como uma pesquisa aplicada. Segundo Vilaça (2010, p. 64-65), a pesquisa aplicada objetiva “[...] contribuir para fins práticos, visando a solução mais ou menos imediata do problema encontrado na realidade". Neste caso, a pesquisa contribuirá para entender 
a atual situação e auxiliar na proposta do modelo de logística reversa realizado.

Para realizar a comparação entre os dois cenários, pontos-chave identificados no país anglo-saxão foram propostos como parâmetro, tais como: disponibilidade de informações ao consumidor e ao desmantelador, facilidade de entrega do automóvel, destinos para as peças, incentivos governamentais e outros.

Dessa forma, a aplicação do questionário apresentado nas figuras 5, 6 e 7 é utilizada como meio para a coleta dos dados brasileiros.
O questionário é dividido em quatro categorias de análise: (1) dados da empresa, (2) de mercado (método de trabalho utilizado e percepção da empresa entrevistada em relação ao mercado), (3) destino preferencial de cada grupo de partes e (4) destino secundário para as peças que não são processadas da maneira tradicional.Estes dados foram coletados através de dezessete perguntas de resposta aberta, onde o entrevistado relatava a realidade da empresa no contexto da pergunta. Este relato foi então comparado com os demais, a fim de categorizar respostas semelhantes.

Figura 5: Questionário para coleta de informações

LD da UC Sistema Digitais - Etapa DE Adequação da linguagem

\section{Entrevista presencial com empresas de ferro-velho}

Entrevista feita com empresas que manuseiam VFV como parte da elaboração do TCC entitulado: "PRÁTICA DE LOGÍSTICA REVERSA DE AUTOMÓVEIS EM FIM DE VIDA EM BLUMENAU-SC: Estudo comparativo com o Modelo Alemão"

\section{Dados da Empresa e do entrevistado}

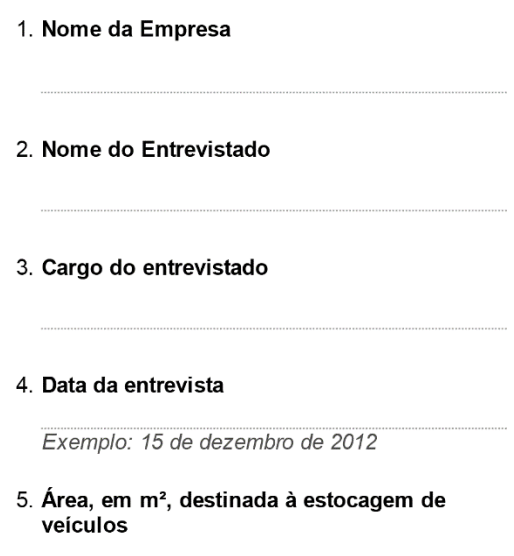

\section{Dados de Mercado}

6. Quantos carros, em média, são recebidos por mês?

7. Qual a procedência dos carros que chegam à empresa? 
Figura 6: Questionário para coleta de informações

8. Como ocorre o processamento do carro?

Como funciona o desmonte, o que acontece com os líquidos, baterias, etc.

9. Como o cliente fica sabendo que a empresa recolhe VFVs?

Existe uma associação ou um instituto no qual a empresa está cadastrada como receptora de VFV?

10. Existe algum portal ou entidade que provê informações a respeito dos automóveis? Informações como número de peças, composição/partes de cada automóvel, peças poluentes/perigosas.

11. A empresa recebe algum incentivo do governo, montadoras ou alguma outra entidade?

Houve alguma manifestação por parte de algum órgão governamental/montadora/entidade para saber qual o destino dado aos Veículos em Fim de Vida?

\section{Quais os destinos usuais das seguintes partes?}

12. Equipamentos e acessórios do interior

Fonte: Dos autores (2015) 
Peças que não foram vendidas ou não vale a pena guardá-las, por não servirem mais ou que estão enferrujadas/estragadas.

15. Equipamentos e acessórios do interior

16. Motor, transmissão e outros equipamentos mecânicos

17. Carroceria, chassis e outras partes estruturais

Fonte: Dos autores (2015)

\section{COLETA DOS DADOS}

Inicialmente, foram pesquisados sites do DETRAN/SC, da Junta Comercial de SC e da FATMA, todos órgãos e entidades ligados ao governo. Como as informações necessárias não foram encontradas, fez-se contato via $e$-mail com representantes do DETRAN, que encaminharam o pedido ao setor competente, respondendo que a responsabilidade por esta informação não era do órgão e que este não tinha vínculo algum com este tipo de atividade (reciclagem de VFV).

Constatou-se a inexistência de entidade oficial e atrelada ao governo que reunisse informações completas sobre este mercado em expansão. O fato em si mostra uma disparidade em 
relação à Alemanha. No país anglo-saxônico, a entidade $A r G e$-Altauto reúne informações sobre a reciclagem de automóveis, peças de reposição, softwares para gestão dos recicladores, entre outras funções. Lá é possível encontrar, de maneira simples e rápida, uma lista com todas as empresas licenciadas para lidar com VFV do país.
Utilizando-se de uma abordagem mais regional, foram consultadas listas telefônicas impressas e sites, com pesquisa pela palavrachave: "Ferro-velho", onde, preliminarmente, foram identificadas 17 empresas no município de Blumenau - SC com essa classificação de atividade e em exercício.

\section{RESULTADOS}

A pesquisa com as empresas escolhidas resultou no panorama apresentado na Tabela 1.

Tabela 1: Resultado das visitas às empresas

\begin{tabular}{l|c}
\multicolumn{1}{c|}{ Caso } & Número de empresas \\
\hline Pesquisas aplicadas & 7 \\
\hline Não quiseram responder & 7 \\
\hline Não encontradas (dados desatualizados) & 3 \\
\hline
\end{tabular}

Fonte: Dos autores (2015)

Sete das dezessete empresas do cenário de pesquisa se dispuseram a responder o questionário. A partir da pesquisa, fez-se um comparativo entre o resultado obtido no município de Blumenau e os dados divulgado pela Alemanha.

Buscando comparar as práticas realizadas na Alemanha e no Brasil, as principais características foram divididas em grupos, para que fossem expostas as informações coletadas e então feita a análise com base nestes dados. Os tópicos que apresentaram maior relevância foram:
a) de onde vêm os automóveis coletados pelas empresas;
b) quais os destinos das peças metálicas;
c) quais os destinos das peças não metálicas;
d) como ocorre a remoção dos líquidos e outros materiais perigosos;
e) como ocorre a comunicação desmantelador-cliente;
f) existência de uma ferramenta de infor- mação e consulta para o desmantelador;
g) incentivos oferecidos pelo governo.

\subsection{Origem dos automóveis}

Os automóveis que são destinados ao desmantelamento na Alemanha são oriundos de consumidores, proprietários do mesmo. Isso porque, segundo a diretiva 2000/53/EC da União Europeia (2015a), o proprietário ou 
última pessoa a ter posse do veículo tem a responsabilidade de encaminhar seu automóvel ao destino final. Para isso, os estados membros, incluindo a Alemanha, devem disponibilizar uma rede de pontos de recebimento destes descartes. Em Blumenau, constatou-se que todas as empresas entrevistadas compravam seus automóveis em leilões de VFV de seguradoras, adquiridos com a finalidade de reaproveitar diversas peças para a venda como materiais secundários. Quando questionadas a respeito de recolhimento de VFV de consumidores, as empresas relataram pouca formalização e grandes entraves em relação à baixa da documentação no DETRAN, sinalizando que o veículo não existirá mais.

\subsection{Destino das partes metálicas}

A Alemanha apresenta, nos dados de 2013, as seguintes porcentagens em relação ao destino da porção metálica dos VFV:

a) $86 \%$ é reciclado;

b) $13 \%$ é reaproveitado energeticamente;

c) $1 \%$ é descartado.

Em Blumenau, o destino primário destas peças é a revenda como partes secundárias. Da porção que não é vendida, o destino final, desconsiderando os processos intermediários, é único: a reciclagem.

\subsection{Destino das partes não metálicas}

Para as partes não metálicas, em dados de 2013, a Alemanha apresenta os seguintes números: a) $52 \%$ é reciclado;

b) $24 \%$ é reaproveitado energeticamente;

c) $20 \%$ é revalorizado;

d) $4 \%$ é descartado.

EmBlumenau,29\%dos entrevistados afirmaram que não dão destino às peças não metálicas, além da revenda como parte secundária. Portanto, entre os que afirmaram dar outro destino final, os números são:

a) $61 \%$ é reciclado;

b) $39 \%$ é descartado.

\subsection{Remoção dos agentes perigosos}

$\mathrm{O}$ artigo 6, parágrafo $3 \mathrm{~b}$ da Diretiva 2000/53/EC, dos países membros da união europeia especifica que "materiais perigosos e componentes devem ser removidos e segregados de maneira seletiva para que não contaminem os resíduos subsequentes dos VFV.” (UNIÃO EUROPEIA, 2015a). Já a Diretiva 2008/98/ $\mathrm{EC}$, referente às orientações para resíduos, define que os países membros devem tomar todas as medidas necessárias para garantir que os resíduos sejam recuperados ou feita a disposição sem prejudicar a saúde humana ou prejudicar o meio ambiente(UNIÃO EUROPEIA,2015b). Observa-se, por esse fato, que os países daUnião Europeia, inclusive a Alemanha, são obrigados por lei a realizar o tratamento e destino adequado para estes materiais. Em Blumenau, observouse que $50 \%$ das empresas destinam corretamente os materiais, sendo que os outros 50\% fazem a disposição em vias impróprias. 


\subsection{Meio de comunicação com os clientes}

Para informar aos cidadãos sobre os locais para o encaminhamento dos VFV, com o processo de desmanche com certificado de destruição, na Alemanha, há dois sites principais que cumprem a função: O ArGe-Altauto e o Gesa. Neles, o consumidor informa seu CEP, e o site indica postos de desmantelamento próximos à sua residência. Em Blumenau, os entrevistados afirmaram que não há qualquer formalização para que o proprietário saiba de empresas que ofereçam este serviço. Observou-se ainda que $29 \%$ das empresas ainda não aceitam veículos em fim de sua vida útil, por conta de entraves em relação ao processo de baixa da documentação junto ao DETRAN. Este cenário ainda é agravado pela dificuldade encontrada para identificar as empresas de ferro-velho em Blumenau.ODETRAN/SC,Junta Comercial e FATMA, órgãos públicos correlatos, sequer foram capazes de fornecer tais informações. Foi necessária uma pesquisa informal em listas telefônicas, assim como uma pesquisa de campo para reunir informações a respeito das empresas.

\subsection{Informações para o desmantelador}

No país anglo-saxão, o desmantelador tem à sua disposição informações dadas por fabricantes a respeito do número de série das peças em seus veículos, componentes perigosos contidos no automóvel, além de outros procedimentos para o correto desmanche do automóvel em si. Tais informações foram concentradas no software IDIS, disponibilizado gratuitamente para todas as empresas que efetuam o manejo de VFV. Em Blumenau, as empresas entrevistadas informaram que não há qualquer manifestação do gênero.Elas utilizam pesquisas em ferramentas de busca para identificar as partes de automóveis, e de sua experiência para identificar materiais perigosos.

\subsection{Incentivos}

\section{governamentais}

Conforme detalhado anteriormente, o governo alemão criou, em 2009, o Umweltprämie, programa de incentivo financeiro para que os VFV fossem descartados, em troca de modelos maisnovosecommelhordesempenhoambiental. O programa resultou em um aumento de $426 \%$ em relação ao ano anterior na quantidade de veículos enviados para o desmanche. Dessa forma, o país melhorou seu desempenho na emissão de gases poluentes, ao mesmo tempo que foi capaz de reutilizar ou revalorizar mais que $95 \%$ dos resíduos gerados pelos VFV. Em Blumenau, nenhum dos entrevistados relatou incentivos governamentais desta natureza para as atividades de recuperação e reaproveitamento deste setor.

\subsection{Destino primário das partes}

É possível concluir que, pelos índices de reciclagem e reaproveitamento energéticos das partes geradas por um VFV na Alemanha, que seu destino principal é se transformar em matéria-prima e em outros processos que voltem ao ciclo de produção, ou seja incinerado, para que sua energia seja recuperada. Em Blumenau, constatou-se pelas respostas dos entrevistados que, tanto para peças metálicas como para não metálicas, o destino primário é 
a simples revenda. As peças retiradas dos VFV são limpas e revendidas no mercado secundário de reposição. Isso se deve pelo valor agregado que essas peças têm, que é estipulado pelo preço da mesma peça, porém, nova. Observase que a qualidade inferior apresentada pelas peças reaproveitadas em relação às novas é compensado pelo valor mais baixo, e, portanto, tem atratividade de mercado, na maior parte dos casos. Constatou-se que este fato faz com que as empresas tendam a manter a peça em estoque por um longo período, pois o lucro com ela será muito maior. Sendo assim, o ciclo de vida das peças ocorre de maneira mais lenta do que na Alemanha. Também, verificou-se que o custo de peças e dos automóveis no Brasil é um fator que restringe o ciclo de vida mais rápido em relação ao que é observado na Alemanha, permitindo que consumidores do país tenham automóveis mais novos e eficientes, sem deixar um grande rastro de resíduos no processo.

\section{CONCLUSÃO}

A recente Política

Nacional dos Resíduos

Sólidos MOSTRA QUE O BRASIL

ESTÁ SE COMPROMETENDO

COM UMA MELHOR UTILIZAÇÃO

DE SEUS RESÍDUOS,

PROPONDO METAS PARA

REDUÇÃO DE LIXÕES, ACORDO

DE RESPONSABILIDADE

COMPARTILHADA PELOS

RESÍDUOS GERADOS PARA UM

PRODUTO E INCENTIVANDO

PRÁTICAS DE PREVENÇÃO

E REDUÇÃO NA GERAÇÃO

DE REsíduos. Por ISSO,

ACREDITA-SE QUE O SETOR

AUTOMOBILÍSTICO LOGO TERÁ

A ATENÇÃO VOLTADA PARA

A QUANTIDADE DE RESÍDUOS

GERADA POR SEUS VFV.
Dentre os pontos observados, verificou-se que, ao efetuar uma comparação entre práticas de logística reversa no município de Blumenau e na Alemanha, há:

- a inexistência, no Brasil, de um sistema de informações para os desmanteladores, orientando a respeito de procedimentos de desmantelamento, substâncias perigosas e outras diretrizes, a exemplo do IDIS;

- falta de uma regulamentação concisa no Brasil, que estipule metas, restrições e procedimentos no tratamento de $\mathrm{VFV}$, a exemplo da Diretiva 2000/53/EC, da União Europeia;

- falta de incentivo governamental para estimular o setor, com diminuição da alíquota de imposto para empresas sustentavelmente responsáveis, por exemplo;

- falta de um canal de comunicação direto entre desmanteladores e proprietários, para que o consumidor tome conhecimento do serviço, a exemplo dos sites ArgeAltauto e Gesa; 
- parcela, ainda expressiva, de resíduos que acabam indo para o lixo comum ou outros destinos ambientalmente incorretos.

Um ponto que agrava a efetividade do processo blumenauense de manuseio de VFV diz respeito à limitação sustentável. Embora o mercado de peças secundárias tenha a vantagem de reutilizar peças que ainda apresentam qualidade, a falta de demanda para parte delas faz com que as mesmas fiquem em estoque por longo período de tempo, interrompendo o ciclo de vida por longos períodos, impedindo que este material seja aproveitado como matéria-prima.

Contudo, apesar da diferença na maneira com que os VFV são tratados atualmente em Blumenau, algumas práticas podem ter seu desenvolvimento iniciado prontamente, como a criação de uma política complementar à PNRS, para regulamentar o setor. A criação de melhores informações para desmanteladores e um canal de comunicação mais direto entre cliente e empresa são medidas observadas na Alemanha, que, quando implantadas, poderão ter impactos positivos em Blumenau e no Brasil. Outra sugestão é verificar a possibilidade de remoção do agente intermediário entre ferrovelho e recicladores, buscando tornar mais atrativo o resíduo reciclável.

A longo prazo, é vista a oportunidade de migrar o destino principal das peças do mercado secundário para a reciclagem propriamente, a exemplo do que acontece na Alemanha. Porém, esta migração depende de diversos fatores, como a diminuição da atratividade das peças secundárias, pela diminuição do preço de automóveis novos, por exemplo. Como sugestão, a realização de uma análise a respeito da presença do intermediador entre ferro-velho e empresa recicladora mostra-se importante, com o objetivo de descobrir o papel que este exerce no processo, se este se faz necessário, ou se é economicamente mais vantajoso criar um fluxo direto. O grande potencial desta análise é aumentar a atratividade das peças de um VFV para a reciclagem. 
REVERSE LOGISTICS

PRACTICE OF

VEHICLES IN END OF

LIFE: COMPARISON

STUDY WITHTHE

GERMAN MODEL OF

VEHICLES IN END OF

LIFE DESTINATION

\begin{abstract}
Due to the growth of global auto market, the concern with the reuse of resources used to manufacture a vehicle is becoming more evident. In this context, this studyobjectives comparing the reverse logisticpractices for vehicles in end of life in Blumenau (Brazil) and Germany. The approach isjustified by the greatpotential on generating vehicles in end of life, since the city of Blumenau has an average of vebicles per habitant that is 1.7 times higher than the national average. $A$ search was made, through aliterature search, gathering information about the characteristics of vehicles in end oflife processing, followed by an applied questionnaire to the junkyard companies of the city. It was found that the handling of vebicles in end of life in Blumenau is made with the sole purpose of reselling the parts removed. In the European country, the focus is on the reuse of raw materials, especially through recycling and energetic reuse. Specific legislations, higher number of information for dismantlers, governmental incentives, simplification of the recycling process and higher company-customer closeness were observed in Germany, while the same does not occur in Blumenau. An alternativescenariosuch thiscould make the vebicle in end oflifereturn to the productivechain, thusclosing the lifecycle in a faster and more efficient way than the simple resale in the secondary market.
\end{abstract}

Keywords: Vehicles in end of

life. Reverse Logistics. Vehicle

Recycling.

\section{REFERÊNCIAS}

ARGE-ALTAUTO. ArGe Altauto - Die Seite für den Autoverwerter. ArGe-Altauto. 2015. Disponivel em: $<$ http://arge-altauto.de/ $>$. Acesso em: 17 maio 2015.

BARCELLOS, C. P. Lixo automotivo é responsabilidade da cadeia produtiva. Consultor Jurídico. 2013. Disponivel em: <http://zip.net/ bptqjq>. Acesso em: 03 set. 2015.

BRASIL. PROJETO DE LEI DO SENADO ${ }^{\circ}$ 67, de 2013. Senado Federal, 2015. Disponivel em: <http://zip.net/bctpLZ>. Acesso em: 03 set. 2015.

BRASIL. Lei no 12.305 de 02 de agosto de 2010. Institui a Política Nacional de Resíduos Sólidos; altera a Lei no 9.605, de 12 de fevereiro de 1998; e dá outras providências. Diário Oficial da União, 2010; 3 ago.

FREITAS, H. et al. O método de pesquisa survey. Revista de Administração, São Paulo, 35, julho/ setembro 2000. 105-112.

IBAMA. Programa de controle da poluição do ar por veículos automotores - Proconve. Instituto Brasileiro do Meio Ambiente e dos Recursos Naturais Renováveis. Brasília, 2011.

IBAMA. Programa PROCONVE. IBAMA MMA, 2015. Disponivel em: <http://zip.net/ bmtpFB>. Acesso em: 24 ago. 2015.

JOAQUIM FILHO, J. Tratamento dos Veículos em Final do Ciclo de Vida no Brasil: Desafios e Oportunidades. São Paulo: Instituto Mauá de Tecnologia, 2012. 


\section{SOBRE OS AUTORES}

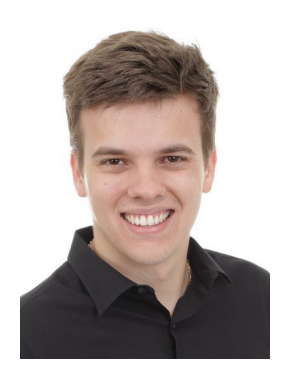

Mateus Wieser

Pamplona

Graduando em Engenharia de Produção pela FURB.Por conta da formação acadêmica, tem experiência na área de

LEITE, P. R. Logística Reversa: meio ambiente e competitividade. 2. ed. São Paulo: Pearson Prentice Hall, 2009.

MILDEMBERGER, L. Avaliação dos principais aspectos da reciclagem de veículos em fim de vida: comparação dos procedimentos legais, técnicos e administrativos entre Alemanha e Brasil. Curitiba: Universidade Federal do Paraná, 2012.

UBA; BMU. Jahresbericht über die AltfahrzeugVerwertungsquoten. Bundesministerium für Umwelt, Naturschutz, Bau und Reaktorsicherheit. Dessau-Roßlau, 2015.

UNIÃO EUROPEIA. Directive 2000/53/EC. EUR-Lex. 2015a. Disponivel em: <http://zip.net/ bytp6H>. Acesso em: 10 nov. 2015.

UNIÃO EUROPEIA. Directive 2009/98/EC. EUR-Lex. 2015b. Disponivel em: <http://zip.net/ bttqmV >. Acesso em: 10 nov. 2015.

VDA. Verband der Automobilindustrie. VDA Global Automotive Economy: Global Market Stronger than Expected. 2014. Disponivel em: <http://zip.net/bytp6J>. Acesso em: 21 mar. 2015.

VILAÇA, M. L. C. Pesquisa e ensino: considerações e reflexões. e-scrita, Nilópolis, I, n. 2, Agosto 2010. 59-74.

Data de recebimento: 09/10/2015

Data de publicação: 29/07/2016 melhoria de processos, com ênfase em manufatura enxuta, em planejamento e controle da produção e também em tecnologias para aproveitamento dos materiais. Tem experiência profissional nas áreas de desenvolvimento de produto, análise de processos, planejamento de controle da produção e implantação de ERP.

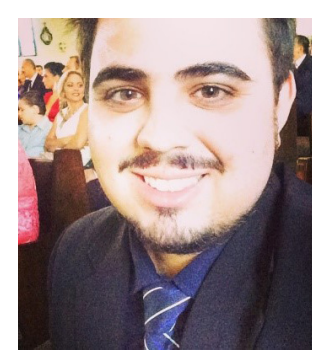

\section{Rodrigo Catafesta} Francisco

Engenheiro CivilpelaFURB

- Fundação Universidade RegionaldeBlumenau(2014). Mestrando no Programa de Pós-graduação em Engenharia Ambiental PPGEA/FURB. Por conta da formação acadêmica, tem experiência na área de Engenharia Civil, com ênfase em construção civil, atuando principalmente nos seguintes temas: agregados, concreto, concreto de alto desempenho e dosagem. No mestrado, desenvolve pesquisa na área de monitoramento de políticas públicas na bacia do Itajaí, atuando nos seguintes temas:planos de recursos hídricos embacias hidrográficas, planos municipais de saneamento básico, políticas públicas, esgotamento sanitário, adequações técnicas, monitoramento e controle. 


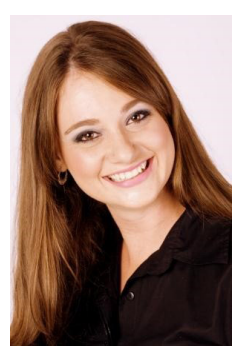

\section{Jaqueline Hertel}

Bióloga pela Fundação Universidade Regional de Blumenau - FURB. Mestranda no Programa de Pós-Graduação em

Engenharia Ambiental-PPGEA/FURB.Por conta da formação acadêmica, tem experiência na área de Parasitologia, com ênfase em Protozoologia de Parasitos e também em processos de Licenciamento Ambiental.No mestrado, desenvolve pesquisa naárea deMonitoramento e Controle Ambiental comênfase em tratamento de águas e efluentes. Tem interesses profissionais de atuação nas áreas Administrativa, Docência e Pesquisa, voltadas para área ambiental ou laboratorial.

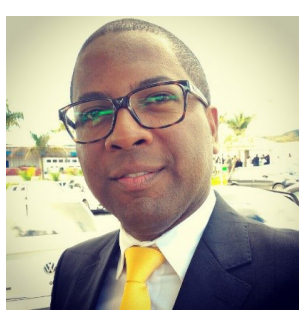

\section{Joel Dias da Silva}

Engenheiro sanitarista pela UFMT - Universidade Federal de Mato Grosso (1999), com Mestrado (2002) e Doutorado (2007) em Engenharia Ambiental, ambos pela UFSC Universidade Federal de Santa Catarina. Realizou o seu Pós-Doutorado em Engenharia Ambientaljunto à FURB - Universidade Regional de Blumenau pelo Programa MEC/CAPES PNPD. Atualmente é professor titular lotado no Departamento de Engenharia de Produção e Design e do Mestrado eDoutorado em Engenharia Ambientaldo Programa de Pós-Graduação (PPGEA) da FURB. Instrutor nível HV-01 do curso superior de tecnologia em Gestão Ambiental dos cursos técnicos em Controle Ambiental, edificações e segurança do trabalho no SENAI Blumenau, em Santa Catarina. Professor colaborador do Mestrado profissionalizante em Engenharia Ambiental, com ênfase em Gestão Ambiental,umaparceriaentreaUFSC-Universidade Federal de Santa Catarina - e o ICE - Instituto de Competências Empresariais - representando a FIAT Automóveis, em Belo Horizonte, Minas Gerais. Consultor Ad Hoc da FACEPE-Fundação de Amparo à Ciência e Tecnologia do Estado de Pernambuco. Possui experiência na grande área da Engenharia Sanitária e Ambiental, com ênfase em resíduos sólidos urbanos e industriais, assim como em efluentes industriais e tecnologias de tratamento. Representante daABES-SC no Conselho Municipal de Saneamento em Blumenau.

*** 